\title{
LEGISLATIVO E POLÍTICA COMERCIAL: AAPROVAÇÃO DO TLC COM OS ESTADOS UNIDOS NOS LEGISLATIVOS SUL-AMERICANOS
}

\author{
Pedro Feliú Ribeiro
}

\begin{abstract}
RESUMO
O artigo analisa as votações nominais de três poderes legislativos sul-americanos, Chile, Colômbia e Peru, acerca da ratificação do Tratado de Livre Comércio com os Estados Unidos. A pergunta central é: quais são os fatores determinantes do voto do legislador na aprovação do Tratado de Livre Comércio (TLC) com os Estados Unidos? Três fatores centrais emergem da literatura: (i) as relações Estados Unidos x América Latina produzem uma clivagem ideológica (direita-esquerda) entre os partidos politicos do continente; (ii) o pertencimento do legislador à coalizão de governo no poder Legislativo e (iii) os fatores sócio-econômicos dos distritos eleitorais dos legisladores. Por meio da utilização do modelo de regressão logística, apontamos que a ideologia dos legisladores peruanos explica os votos dos mesmos no TLC com os Estados Unidos, indicando que quanto mais à esquerda estiver o legislador, menor a probabilidade do mesmo aprovar o referido tratado. No caso chileno, a taxa de desemprego do distrito eleitoral do deputado possui maior capacidade explicativa, revelando que quanto maior a taxa de desemprego, menor a probabilidade de aprovação do TLC com os Estados Unidos. Já no caso do Senado colombiano, há uma forte associação entre o pertencimento do Senador à coalizão de governo e a aprovação do TLC, revelando a influência dessa variável institucional no voto do Senado colombiano. Além do pertencimento ou não à coalizão de governo, a ideologia do partido político do legislador colombiano também se apresenta como fator explicativo relevante do voto do mesmo.
\end{abstract}

PALAVRAS-CHAVE: política comercial; poderes legislativos sul-americanos; TLC; Estados Unidos.

\section{INTRODUÇÃO}

Os processos de redemocratização e liberalização econômica, predominantes a partir da década de1990 em boa parte dos países da América Latina, redesenharam o perfil político e econômico dos mesmos, introduzindo modificações significativas na formulação das políticas comerciais. Países como Chile, Colômbia, Peru, México, Costa Rica e República Dominicana, entre outros, celebraram diversos tratados de livre comércio da década de 1990 aos dias atuais. Essa liberalização comercial intensificou a internacionalização da agenda doméstica dos países, gerando a incidência desigual dos custos e benefícios da liberalização comercial na sociedade (conseqüências distributivas). Também comum a esses países é a prerrogativa constitucional dos congressos nacionais em apreciar a ratificação dos acordos internacionais, tornando a instituição um possível ponto de veto no processo decisório da política comercial. Uma vez assinado o acordo comercial, cabe aos legisladores decidirem a implementação ou não do mesmo, sendo o Congresso Nacional a última instância decisória de representação política da sociedade.

Sendo assim, compreender os determinantes do voto do legislador sul-americano na apreciação dos acordos internacionais de política comercial é o objetivo geral do presente artigo. Mais especificamente, analisamos a aprovação dos tratados de livre comércio com os Estados Unidos nos poderes legislativos de Chile, Colômbia e Peru. Duas características essenciais justificam a escolha desse tratado. Primeiro, o Tratado de Livre Comércio (TLC) com os Estados Unidos ocupou uma posição central na agenda comercial desses países, dada a elevada representatividade da economia norte-americana nas balanças comerciais dos mesmos. Espera-se, portanto, conseqüências distributivas oriundas da implementação do tratado significativas, sensibilizando o eleitorado e os interesses 
organizados da sociedade de forma ampla. Segundo, embora haja algumas diferenças substantivas nos distintos tratados assinados nos três países, a coincidência dos Estados Unidos como parte contratante elimina o problema do viés de seleção na comparação entre os determinantes do voto dos legisladores nos três países. Como estamos tratando da mesma matéria, é possível comparar os resultados dos três países, possibilitando uma compreensão um pouco mais ampla acerca da conformação das preferências dos legisladores do subcontinente na tomada de decisão em política comercial.

Na seção 2 do presente artigo apresentaremos a revisão bibliográfica acerca dos determinantes do voto do legislador na política comercial, indicando três conjuntos de variáveis explicativas centrais: (i) fatores sócio-econômicos do distrito eleitoral e interesses organizados, (ii) ideologia e (iii) fatores institucionais. Na seção 3, apresentamos a amostra do estudo, assim como as hipóteses a serem testadas e suas respectivas lógicas explicativas e descrição das variáveis. $\mathrm{Na}$ seção 4 exibimos os resultados dos modelos de regressão logística, a saber, a importância das seguintes variáveis: $(i)$ desemprego na explicação dos votos dos deputados chilenos; (ii) ideologia no caso dos legisladores peruanos e, no caso colombiano, a combinação entre o pertencimento ou não do legislador à coalizão de governo e, por fim, (iii) a ideologia do partido político do legislador.

\section{REVISÃO DA LITERATURA}

Um debate bastante presente nos estudos sobre comportamento legislativo busca compreender os determinantes do voto nominal dos congressistas no conjunto das políticas públicas. No que se refere à política comercial mais especificamente, podemos dividir os argumentos centrais da literatura em dois grandes conjuntos. No primeiro conjunto, os votos dos legisladores são explicados por variáveis exógenas ao processo legislativo, resumindo-se em três principais: (i) os interesses organizados via contribuição de campanha ou pressão política, (ii) a ideologia dos legisladores e (iii) as condições econômicas e sociais dos distritos eleitorais dos mesmos. No segundo conjunto, as variáveis explicativas acerca do posicionamento dos legisladores em temas de política comercial são endógenas ao processo legislativo, configurando-se como variáveis institucionais. São alguns exemplos o poder de agenda do Presidente, a disciplina partidária, o desenho do sistema eleitoral e a estruturação das comissões legislativas e suas prerrogativas. É evidente que é possível observar uma interessante intersecção entre ambos os conjuntos explicitados, mesclando explicações institucionais e societais acerca do voto do legislador em política comercial.

\section{II.1. Os fatores explicativos exógenos}

Considerando o primeiro conjunto de variáveis explicativas citado acima, a lógica desses modelos fundamenta-se na relação causal entre fatores econômicos, sociais, políticos e o voto do legislador. Baldwin e Magee (2000), ao analisarem as votações nominais no congresso norteamericano acerca das aprovações do Tratado Norte-Americano de Livre Comércio (Nafta, na sigla em inglês), tratados da Rodada Uruguai e a renovação do "fast-track authority", testam a relação entre votar a favor ou contra e três conjuntos de variáveis: $(i)$ condições econômicas e sociais nos distritos eleitorais dos legisladores como, por exemplo, a proporção da força de trabalho com menos do que o colegial completo, a proporção de trabalhadores sindicalizados, taxas de desemprego e cifras de exportação e importação dos distritos; (ii) a ideologia dos legisladores e (iii) as contribuições de campanha executadas por interesses organizados. Os autores argumentam que os três fatores testados influenciam o comportamento (voto) do legislador norteamericano frente essas questões de política comercial. No que tange as contribuições de campanha, legisladores que recebiam financiamento de sindicatos ("labor contributions") possuíam maior probabilidade de votar de maneira contrária ao Nafta, por exemplo. Analogamente, aqueles legisladores que receberam alguma contribuição do empresariado ("business contributions") teriam uma maior propensão a votar de maneira favorável ao citado tratado comercial. Do ponto de vista das condições econômicas e sociais dos distritos eleitorais, aqueles legisladores que representavam distritos com maiores taxas de desemprego tendiam a votar de maneira contrária ao Nafta, por exemplo. Finalmente, com relação à ideologia dos legisladores, surpreendentemente, legisladores classificados como conservadores tenderam a votar contrariamente ao Nafta (idem, p. 28-30). 
II.2. A influência dos fatores econômicos e sociais do distrito do legislador

Alguns estudos têm corroborado a percepção da importância das características sócioeconômicas dos distritos eleitorais na conformação das preferências dos legisladores nas decisões de política comercial. Henisz e Mansfield (2006) indicam uma forte correlação entre a deterioração das condições macroeconômicas dos distritos e o aumento das demandas protecionistas emanadas da sociedade. Desse modo, os legisladores sofrem maior pressão protecionista de seu eleitorado quando o desempenho econômico de seus distritos é ruim. Dentre as condições econômicas mais influentes na decisão do parlamento acerca da polícia comercial, a taxa de desemprego é a mais crucial (idem, p. 191). Há, nessa perspectiva, o entendimento de que os tomadores de decisão em política comercial estão constrangidos pelo chamado "viés organizacional". Isto é, aqueles grupos que perdem com a abertura comercial possuem um maior incentivo a organizar-se do que aqueles que se beneficiam da mesma. $\mathrm{O}$ resultado seria uma super-representação dos interesses protecionistas junto aos legisladores, influenciando seus votos na direção apontada (BAILEY, GOLDSTEIN \& WEINGAST, 1997).

Persistindo nessa linha explicativa, Conley (1999) compara as votações nominais acerca da resolução de aprovação da outorga do fast-track em 1991 e a não aprovação da renovação do mesmo fast-track em 1997. O autor observa que o efeito da variável "ideologia" cai 27 pontos de 1991 a 1997, enquanto as pressões dos constituintes desempenharam um papel central na oposição do congresso norte-americano ao Presidente Clinton, especialmente entre os democratas. $\mathrm{O}$ fato mais surpreendente é o apoio legislativo democrata à aprovação do fast-track no governo republicano em 1991 e a oposição do mesmo partido no congresso quando o governo era democrata. Aqueles legisladores representando distritos caracterizados como labor oriented (forte presença sindical no distrito) apresentaram uma tendência maior a votar desfavoravelmente ao fasttrack, em 1997, quando comparado a 1991, demonstrando a crescente preocupação democrata com o eleitorado trabalhista (idem, p. 791).

\section{II.3. A influência dos interesses organizados}

Lowi (1964) argumenta que o cálculo dos custos e benefícios eleitorais dos legisladores (reeleição) é significativamente afetado pela influência dos grupos de interesses especiais, fundamentalmente pela optimização do retorno eleitoral via contribuição de campanha e a ameaça de perda de votos por meio de, por exemplo, demissões massivas, desvios de investimentos, entre outros. Exemplos de estudos que apontam o lobby como variável explicativa primordial da tomada de decisão de legisladores em política comercial são Fordham e McKeown (2003), Hall e Deardorff (2006), Ehrlich (2008), entre outros.

As teses que associam decisões dos legisladores em política comercial a atuação dos grupos de interesse sugerem, por exemplo, que é irrelevante a ideologia dos partidos políticos com relação ao tema (RAY, 1981). Como a política comercial é resultado das preferências e influências dos grupos de interesse, a ideologia dos partidos políticos é irrelevante na medida em que cada partido tende a representar uma multiplicidade de grupos de interesse com diferentes preferências. $\mathrm{Na}$ visão de Grossman e Helpman (1994), por exemplo, setores econômicos organizados em grupos de interesses especiais tendem a dominar a política comercial, tornando os partidos políticos agentes com menor poder de influência.

Finalmente, uma importante tese que vincula política comercial a alinhamentos políticos originados pela abundância ou escassez de determinados fatores produtivos foi produzida por Rogowski (1989). Apropriando-se do teorema Stolper-Samuelson, Rogowski (idem) sustenta que os proprietários dos fatores produtivos abundantes tenderão a demandar abertura comercial, enquanto aqueles proprietários de fatores produtivos escassos estariam inclinados a demandar protecionismo. Neste sentido, legisladores que sofrem o lobby dos proprietários de fatores produtivos escassos no país tendem a sofrer forte pressão protecionista desse grupo afetado por uma eventual abertura econômica, induzindo as preferências desses legisladores nessa direção. O inverso ocorre naqueles distritos cujo legislador sofre a influência dos proprietários de fatores produtivos abundantes no país, ocorrendo a demanda por liberalização. Complementariamente, Hiscox (2002) argumenta que mudanças na mobilidade dos fatores produtivos capital e trabalho dos distritos eleitorais causam um impacto significativo na formulação da política comercial norte-americana. 


\section{II.4. O papel da ideologia do legislador nas} decisões de política comercial

De uma maneira geral, a literatura que identifica a ideologia como variável preditiva do comportamento parlamentar em temas de política comercial busca compreender a associação entre o posicionamento dos legisladores no contínuo direita - esquerda e as opções políticas representadas pelo contínuo liberalismo protecionismo. Milner e Judkins (2004), por exemplo, examinam o posicionamento dos partidos políticos em temas de política comercial em 25 países desenvolvidos (a maioria da Organização para a Cooperação e Desenvolvimento Econômico (OCDE)) entre 1945 e 1998. O argumento central desse estudo é a existência de um forte impacto do posicionamento dos partidos políticos, em uma escala ideológica unidimensional direita-esquerda, e as posições tomadas pelos políticos e legisladores dos mesmos em temas de política comercial. Ademais, na amostra desse estudo, os partidos de esquerda tenderam a favorecer o livre comércio, enquanto os de direita posicionaram-se contra (idem).

Tendo em vista o caso de legislativos sulamericanos, Feliú, Galdino e Oliveira (2007), após análise das votações nominais acerca da ratificação dos tratados de livre comércio na Câmara dos Deputados do Chile desde a redemocratização do país, concluem que a localização do partido político do deputado no espectro ideológico direitaesquerda é um excelente preditor dos votos do mesmo em política comercial. Ademais, constatouse que deputados localizados mais à esquerda do espectro tendem a votar favoravelmente ao livre comércio (idem). Outros exemplos de estudos que percorrem esta mesma linha explicativa são Epstein e O'Halloran (1996), Xie (2004) e Marks et alii (2006), entre outros.

II.5. Influências endógenas: as variáveis institucionais

Há uma vasta literatura que analisa as variações institucionais como fator determinante do comportamento dos tomadores de decisão na política comercial. Dada a variedade desse tipo de estudo, encontramos análises desde um escopo mais amplo, como a investigação do impacto do tipo de regime político na formulação da política comercia do país (ROGOWSKI, 1987; BUENO DE MESQUITA, 2000; MANSFIELD, MILNER \& ROSENDORFF, 2000), assim como associações entre sistemas eleitorais e partidários e o comportamento parlamentar no tema.

Uma dimensão importante desta perspectiva é a relação entre o poder Executivo e Legislativo na formulação da política comercial. Milner e Rosendorff (1997), por exemplo, argumentam a propensão do poder Executivo em promover a liberalização comercial e a do poder Legislativo em manifestar posturas mais protecionistas. Como o chefe do poder Executivo é eleito em âmbito nacional, suas preocupações eleitorais centramse no eleitor mediano do país, priorizando políticas que gerem redução do custo ao consumidor e controle inflacionário. O poder Legislativo, por ser responsivo a um eleitorado em nível distrital, estaria mais propenso a representar interesses paroquiais protecionistas.

Nielson (2003), ao analisar países em desenvolvimento, argumenta que presidentes com significativos poderes legislativos e lideranças partidárias fortes são capazes de superar os interesses protecionistas, promovendo a abertura comercial. Assim, a delegação de poderes do legislador ao Presidente e à liderança partidária está intimamente ligada à liberalização comercial. O autor também sugere o efeito positivo do tamanho do distrito eleitoral no nível de liberalização comercial (idem, p. 489).

No que tange as associações entre sistemas eleitoral e partidário e a decisão dos legisladores em política comercial, McGillivray (1997) desenvolve uma teoria relacionando os níveis de disciplina partidária e o nível de proteção econômica advinda de poderes legislativos com sistema eleitoral majoritário uninominal (single-member districts). Similarmente, Hankla (2006) postula haver uma correlação direta entre disciplina partidária e decisões liberalizantes. Quanto mais disciplinado for o partido, maior será a tendência de que promova posturas abrangentes, portanto, liberalizantes. Rogowski (1987) sustenta que policy-makers em países com sistemas de representação proporcional com distritos de grande magnitude encontram-se mais isolados de pressões protecionistas advindas da sociedade. Nos sistemas majoritários, ao contrário, o tomador de decisão situa-se mais exposto a pressões protecionistas.

Milner e Kubota (2003) argumentam que quanto maior o tamanho da coalizão societal (inclui todos os grupos de interesse organizados) maior 
será a tendência do tomador de decisão adotar medidas liberalizantes com o intuito de beneficiar um número maior de atores. Por outro lado, coalizões societais menores, muito comuns em regimes autocráticos, incentivam o tomador de decisão a revelar posturas mais protecionistas, redistribuindo a renda daqueles que não participam da estreita coalizão.

É interessante notar o trabalho de Karol (2007) como contraponto aos argumentos que correlacionam sistema eleitoral e política comercial. Ao analisar o papel do tamanho dos distritos na conformação das preferências dos tomadores de decisão em política comercial, Karol (idem) sustenta a não equivalência entre interesses distributivos e demanda por proteção. $\mathrm{O}$ ponto central é questionar algumas premissas adotadas pela literatura, como a irrelevância dos partidos políticos, a maior relevância dos interesses protecionistas e, principalmente, a orientação protecionista dos tomadores de decisão calcada na existência de incentivos institucionais que induzem o legislador a beneficiar interesses concentrados (distritais) em detrimento de interesses difusos (nacionais). Um distrito exportador e competitivo, por exemplo, pode demandar por maior integração regional ou liberalização comercial a despeito das forças protecionistas contrárias.
Muitas das teorias expostas brevemente na revisão bibliográfica acima são calcadas no caso norte-americano, com exceção evidente dos estudos comparados. Não se buscou aqui realizar uma revisão exaustiva, privilegiando o apontamento das principais relações explicativas para o voto do legislador presentes na literatura. Não obstante, não há muitos estudos que focam no caso dos legisladores sul-americanos sobre o tema, possivelmente pela percepção, cada vez mais contestada, da baixa relevância do poder Legislativo no processo de implementação da política comercial (OLIVEIRA \& ONUKI, 2010). Nesse sentido, o problema de pesquisa proposto neste estudo é: quais os determinantes do voto do legislador sul-americano na política comercial? $\mathrm{Na}$ seção seguinte, abordaremos a metodologia empregada para responder a pergunta, assim como exporemos a amostra selecionada.

\section{O DESENHO DA PESQUISA}

A escolha do Chile, Colômbia e Peru para conformar a amostra da pesquisa deriva da combinação de quatro fatores essenciais: o uso da votação eletrônica nos legislativos nacionais ${ }^{1}$, a apreciação de acordo comercial com os Estados Unidos, um nível mínimo de polarização entre os votos favoráveis e contrários ao acordo ${ }^{2} \mathrm{e}$ pertencer ao subcontinente sul-americano. A Tabela 1, abaixo, expõe algumas informações sobre a amostra proposta.

\section{TABELA 1-AMOSTRA}

\begin{tabular}{|l|ccc|c|}
\hline País & Casa legislativa & Ano de apreciação & Votos favoráveis & $\begin{array}{c}\text { Votos } \\
\text { contrários }\end{array}$ \\
\hline Chile & Deputados & 2003 & 87 & 8 \\
Colômbia & Senado & 2007 & 49 & 16 \\
Peru & Unicameral & 2006 & 78 & 14 \\
\hline
\end{tabular}

FONTES: Elaboração do autor, a partir de Chile (2013), Congreso Visible (2008) e Peru (2013).

Como podemos observar na Tabela 1, os anos de apreciação dos acordos analisados são bastante próximos, variando entre 2003 e 2007. A escolha das casas legislativas exposta acima justifica-se da seguinte forma: no caso do Chile optou-se pela Câmara dos Deputados pelo fato dessa casa legislativa, quando comparada ao Senado, possuir um maior número de membros. Isso favorece o emprego de métodos quantitativos de análise, como será descrito abaixo. No caso colombiano,
1 Para obter a lista de legislativos sul-americanos que fazem uso ou não do registro eletrônico dos votos nominais e os disponibilizam na internet, ver Saiegh (2005).

2 Apenas para registro, o México e a República Dominicana, países da América Latina, disponibilizam as votações nominais acerca da aprovação do TLC com os Estados Unidos. No caso do Senado mexicano, 55 votos foram favoráveis e dois foram contrários. $\mathrm{Na}$ Câmara dos Deputados da República Dominicana, 118 deputados foram favoráveis ao acordo enquanto apenas quatro votaram 
o Senado foi escolhido pela disponibilidade dos dados da votação nominal. Finalmente, o caso do Peru é o mais peculiar, uma vez que, ao contrário dos demais casos, o poder Legislativo é organizado na forma unicameral.

Para identificar os fatores que melhor explicam os votos dos legisladores sul-americanos na aprovação dos tratados de livre comércio com os Estados Unidos, utilizamos a análise de regressão logística. Essa técnica estatística é apropriada para a análise em questão, dado que a regressão logística é utilizada para estimar uma variável categórica, geralmente dicotômica, em função de um conjunto de variáveis preditoras. No caso aqui analisado, a variável resposta são os votos dos legisladores na aprovação do TLC com os Estados Unidos, variando categoricamente entre um ("sim") e zero ("não"). Quando fazemos o uso de uma variável resposta categórica, como é o nosso caso, a função discriminante é comumente utilizada quando as variáveis preditoras são contínuas e bem distribuídas, logit quando todas as variáveis preditoras são categóricas e, finalmente, a regressão logística quando as variáveis preditoras são um misto entre variáveis contínuas e variáveis categóricas, não fazendo uso de nenhum pressuposto acerca da distribuição das variáveis preditoras (WUENSCH, 2009). Nessa investigação, como será explicitado abaixo, fazemos uso de variáveis preditoras contínuas e categóricas, tornando a regressão logística o teste estatístico mais adequado.

Analisaremos essencialmente a dimensão espacial da regressão logística, conduzindo uma análise do tipo cross-sectional, ou seja, as variáveis resposta e explicativas estão associadas a um recorte temporal específico ou, em outras palavras, um ponto no tempo. No caso aqui proposto cada legislador vota em um ano específico a aprovação do TLC com os Estados Unidos, onde as variáveis explicativas correspondem ao ano da votação do TLC, como uma foto tirada de um espaço temporal contínuo. Outro aspecto relevante a ser considerado é o fato da regressão logística, assim como a linear, estudar relações entre variáveis, buscando aquelas que

contra. Em nenhum dos dois casos o lado minoritário ultrapassou $10 \%$ do majoritário. É importante frisar que os votos “abstenção" foram descartados da análise. podem influenciar de alguma forma a variável resposta. A diferença central é que a regressão logística fornece uma resposta em probabilidade de chances de ocorrer o evento estudado. No nosso caso, estima-se a probabilidade do legislador votar "sim" ou "não" dada a presença de algumas variáveis preditoras. Seguem abaixo as variáveis incluídas no modelo e suas respectivas hipóteses.

\section{III.1. Hipóteses e variáveis preditoras}

Para selecionar as variáveis preditoras do modelo de regressão logística, assim como as respectivas hipóteses, utilizamos como referência os principais fatores explicativos presentes na literatura e expostos na seção 2 deste artigo. Dessa forma, buscaremos instrumentalizar aspectos institucionais, as condições sócio-econômicas dos distritos eleitorais $^{3}$, a ideologia do legislador e a influência dos interesses organizados na construção do modelo explicativo. Abaixo seguem dispostas as hipóteses e respectivas variáveis preditoras do modelo proposto.

\section{III.1.1. Condições sócio-econômicas do distrito do} legislador

Entre as condições macroeconômicas mais influentes na política comercial (trade policy), o desemprego é crucial. Nas palavras de Henisz e Mansfield (2006, p. 191), "perhaps the most crucial factor - and the one that most likely to influence policy choice toward protection - is the extent and duration of existing unemployment"4. A lógica envolvida na relação entre desemprego e influência na política comercial é a seguinte: é esperado que altas taxas de desemprego produzam demandas por protecionismo na medida em que se torna mais difícil para os trabalhadores ajustarem-se frente ao aumento das importações. Aqueles trabalhadores que perderam emprego em virtude do aumento da competição dos produtos

\footnotetext{
3 O Senado colombiano elege 100 candidatos por meio de uma lista nacional e dois membros por meio de uma lista especial indígena, ou seja, a magnitude do distrito eleitoral neste caso é 100 para a maior parte dos senadores. Por esse motivo, utilizamos o departamento que mais votou no Senador como proxy da filiação departamental do mesmo Esses dados foram obtidos em Congreso Visible (2008), acessado em 20 de julho de 2010.

4 "Talvez o fator mais crucial - e aquele que mais deve influenciar a escolha política pela proteção - é a extensão a duração do desemprego existente" (Nota do revisor).
} 
importados terão grande dificuldade de conseguir outro emprego e/ou manter o mesmo nível salarial. Esses trabalhadores, somados àqueles cujo medo de perder o emprego é grande, têm fortes razões para pressionar o governo e o poder Legislativo por proteção (idem). Segundo Olson (1982), altos índices de desemprego estimulam trabalhadores, investidores e outros grupos de interesse afetados adversamente pela abertura comercial a superarem o problema da ação coletiva e mobilizarem-se para exigir políticas que reduzam a abertura comercial. Por tal motivo, para medir a influência das condições sócio-econômicas do distrito eleitoral do legislador, recorreremos às taxas de desemprego dos respectivos distritos no ano de apreciação do acordo comercial com os Estados Unidos $^{5}$. Assim, a primeira hipótese do artigo configura-se da seguinte maneira: H1: quanto maior a taxa de desemprego do distrito do legislador, maior a probabilidade deste votar contrariamente ao Acordo de Livre Comércio com os Estados Unidos.

Outra variável distrital incluída no modelo de regressão logística é o volume das exportações dos distritos eleitorais ${ }^{6}$. Essa variável visa medir os diferentes impactos econômicos causados pelo setor externo do país nos distritos eleitorais do mesmo. Em geral, os grupos econômicos exportadores são favoráveis aos acordos de livre comércio, principalmente quando vislumbrado um mercado enorme como o norte-americano. Assim, espera-se que distritos que exportam mais apresentarão uma maior pressão em prol da aprovação do acordo. Formula-se, portanto, a segunda hipótese para os casos de Peru e Colômbia: H2: legisladores pertencentes a distritos exportadores possuem uma maior probabilidade de votar favoravelmente ao TLC com os Estados Unidos.

Finalmente, ainda referente às variáveis distritais, utilizamos a porcentagem da população economicamente ativa no primeiro setor da economia $^{7}$ (setor agrícola). Nas discussões

\footnotetext{
5 As taxas de desemprego dos distritos chilenos foram obtidas em Casen (CHILE, 2003), no caso peruano INEI (PERU, 2007) e no caso colombiano DANE (PERU, 2007).

6 No caso dos distritos eleitorais chilenos não foi encontrada essa variável para ser incluída no banco de dados.

7 Não foi possível encontrar esse dado para o caso colombiano, impossibilitando a inclusão dessa variável no modelo logístico do Senado colombiano.
}

realizadas nos congressos nacionais de Chile e Peru acerca da ratificação do TLC com os Estados Unidos, congressistas provenientes de setores agrícolas que competem com similares norteamericanos, fundamentalmente trigo e algodão, expressaram a sua preocupação com a sobrevivência desse grupo econômico caso o tratado fosse aprovado. Um dos argumentais centrais foi a desleal competição que esses setores agrícolas enfrentariam frente aos elevados subsídios agrícolas praticados pelo governo norteamericano. Espera-se, portanto, que congressistas provenientes de distritos caracterizados por uma proporção significativa de trabalhadores situados no primeiro setor rejeitem o acordo como tentativa de proteger o setor da competição norteamericana. Formula-se a terceira hipótese: H3: legisladores pertencentes a distritos dotados de elevada proporção de trabalhadores no primeiro setor possuem uma maior probabilidade de votar contrariamente ao TLC com os Estados Unidos.

\section{III.1.2. Ideologia do legislador}

Saez e Rivas (2006) analisam, por meio de survey aplicado aos legisladores latino-americanos, o posicionamento dos partidos políticos no espectro ideológico direita-esquerda. Um dos conjuntos de perguntas feitas aos legisladores do continente diz respeito à atitude do país nas relações com os Estados Unidos, mais especificamente, as preferências dos legisladores acerca da aprovação da Área de Livre Comércio das Américas (ALCA) e uma possível relação comercial preferencial com os Estados Unidos. Essa dimensão, de acordo com a análise fatorial elaborada pelos autores, explica cerca de $10 \%$ da variância total (ideologia), sendo o terceiro fator explicativo mais relevante. Isso mostra a importância das relações Estados Unidos-América Latina na polarização ideológica dos partidos políticos latino-americanos de um modo geral (idem, p. 6). Ao analisarem as posições dos partidos classificados como esquerda e direita e as preferências dos mesmos em relação ao fator citado, os autores observam uma tendência relevante: nos países da América do Sul os partidos de esquerda tendem a opor-se mais a uma relação preferencial com os Estados Unidos (idem, p. 15). Assim, como estamos averiguando o comportamento legislativo em países sulamericanos, incluímos a ideologia do legislador como possível fator explicativo dos votos dos legisladores acerca do Tratado de Livre Comércio com os Estados Unidos na direção proposta na 
hipótese 4. Para medir a ideologia dos legisladores chilenos e peruanos, utilizamos os scores do NOMINATE (variável contínua) estimados para as votações de política externa nas Legislaturas 2002-2006 da Câmara dos Deputados do Chile ${ }^{8}$ e 2001-2007 no Legislativo peruano. No caso colombiano, utilizamos a classificação ideológica dos partidos políticos para a legislatura 2006-2010 via survey elaborado por PELA (2006). Basicamente, utilizou-se a pergunta do survey que pede aos deputados colombianos classificarem os principais partidos políticos em uma escala ideológica de um (esquerda) a dez (direita). A média dos valores apontados pelos legisladores a respeito dos partidos alheios retorna a posição do partido no espectro ideológico, caracterizando-se como uma variável contínua. Em vez de medirmos a ideologia por legislador, como nos casos chileno e peruano, no caso colombiano medimos por partido. Assim, formula-se a quarta hipótese do estudo: H4: quanto mais à esquerda estiver o legislador no espectro ideológico, maior a probabilidade de rejeitar o TLC com os Estados Unidos.

\section{III.1.3. Variável institucional}

Os principais estudos presentes na literatura (ver seção 2) que averiguam a influência das variáveis institucionais no comportamento legislativo em política comercial comparam muitos países, justamente para lograr certa variabilidade nesse componente. Como no presente artigo comparamos apenas três países, algumas variáveis relevantes utilizadas pela literatura não poderão ser testadas, por exemplo, a magnitude dos distritos eleitorais. Ainda assim, testaremos aqui um importante componente institucional nas decisões dos congressistas do continente: o pertencimento ou não do legislador à coalizão de governo. Importantes estudos sobre os legislativos sulamericanos apontam para a importância do chamado presidencialismo de coalizão, um presidencialismo multipartidarista caracterizado por um presidente institucionalmente capaz de conformar maiorias no congresso, garantindo estabilidade e governabilidade ao sistema político (ver, por exemplo, Mustapic (2002), Nolte (2003)

\footnotetext{
8 Sobre a utilização do NOMINATE para medir os pontos ideais e o posicionamento ideológico dos deputados chilenos, ver Feliú, Oliveira e Galdino (2009).
}

e Limongi (2006)). A maioria legislativa conformada pelo presidente eleito compõe a coalizão governista, sustentada em grande medida pelos amplos poderes legislativos e de agenda do presidente e pela nomeação de cargos executivos. Dessa forma, o presidente induz os parlamentares à cooperação, costumando-se observar elevados índices de disciplina partidária entre os partidos que conformam a coalizão governista. Como o Tratado de Livre Comércio com os Estados Unidos é enviado pelos presidentes aos congressos nacionais, espera-se que os mesmos mobilizem suas bases de apoio para a aprovação da mensagem. Abaixo, formulamos a quinta hipótese: H5: os legisladores pertencentes à coalizão do governo possuem maior probabilidade de votar favoravelmente ao TLC com os Estados Unidos.

\section{RESULTADOS}

Nesta seção apresentaremos os principais resultados obtidos nos modelos logísticos propostos acima. Ao contrário dos casos de Chile e Peru, no Senado colombiano a variável "coalizão" é capaz de explicar as votações perfeitamente, impossibilitando a inclusão dessa variável no modelo logístico colombiano. Esse problema é chamado de separação completa (complete separation), ocorrendo quando se pretende prever um resultado e a explicação converge perfeitamente com o mesmo, não havendo interações capazes de distinguir a diferença entre grupos. Assim sendo, optaremos, para o caso colombiano, por uma estratégia distinta. Primeiro, utilizamos um teste qui-quadrado para medir o nível de associação entre as variáveis binárias "voto" e "coalizão" (ver seção IV.3). Segundo, construímos um modelo logístico sem a variável independente "coalizão"?.

Exporemos também, antes dos resultados dos modelos logísticos dos três países, as estatísticas descritivas das variáveis independentes incluídas nos três modelos. A apresentação desses dados ajuda a compreender melhor as variáveis instrumentalizadas e descritas na seção anterior.

\footnotetext{
9 É interessante notar que quando dicotomizamos a variável "ideologia", atribuindo "0" caso o partido seja de esquerda e "1" de direita, percebemos que as variáveis "coalizão" e "ideologia" são idênticas, ou seja, os partidos classificados como "esquerda" pertencem à oposição e aqueles classificados como "direita" pertencem à coalizão de governo.
} 
TABELA2 - ESTATÍSTICAS DESCRITIVAS VARIÁVEIS EXPLICATIVAS (PERU)

\begin{tabular}{|l|c|c|c|c|}
\hline Variáveis explicativas & Mínimo & Máximo & Média & Desvio Padrão \\
\hline Ideologia & $-1,0$ & 1,0 & .286 & .141 \\
Desemprego & 2,8 & 10 & 6,1 & 1,4 \\
PEA 1 ${ }^{\circ}$ Setor & 5 & 81,1 & 32,8 & 23,4 \\
Exportações (bilhões US $\$$ ) & 0 & 13,9 & 5,4 & 6,5 \\
Coalizão & 0 - oposição; 1 - governo & & \\
N & 93 & & \\
\hline
\end{tabular}

FONTE: $O$ autor.

NOTA: PEA: População Economicamente Ativa.

TABELA3 - ESTATÍSTICAS DESCRITIVAS VARIÁVEIS EXPLICATIVAS (CHILE)

\begin{tabular}{|l|c|c|c|c|}
\hline Variáveis explicativas & Mínimo & Máximo & Média & Desvio Padrão \\
\hline Ideologia & -.982 & .957 & -.091 & .613 \\
Desemprego & 2,3 & 15,3 & 9,5 & 2,4 \\
PEA $1^{\circ}$ Setor & .90 & 44,2 & 16,6 & 13,1 \\
Coalizão & $0-$ oposição; 1 - governo & & \\
N & 95 & & \\
\hline
\end{tabular}

FONTE: O autor.

TABELA4 - ESTATÍSTICAS DESCRITIVAS VARIÁVEIS EXPLICATIVAS (COLÔMBIA)

\begin{tabular}{|l|c|c|c|c|}
\hline Variáveis explicativas & Mínimo & Máximo & Média & Desvio Padrão \\
\hline Ideologia & 2 & 6,6 & 5,11 & 1,48 \\
Desemprego & 9,2 & 15,6 & 10,8 & 1,1 \\
Exportações (bilhões US $\$$ ) & 0,6 & 4 & 1,7 & 1,3 \\
Coalizão & 0 -oposição; 1 - governo & & \\
N & 65 & & \\
\hline
\end{tabular}

FONTE: $\mathrm{O}$ autor.

As tabelas 2, 3 e 4 apresentam medidas descritivas básicas: a amplitude dos dados, indicando os valores mínimos e máximos, a média e o desvio padrão das observações de cada uma das variáveis explicativas contínuas incluídas no modelo de regressão logística para os casos peruano, chileno e colombiano, além da especificação da variável dicotômica "coalizão". Podemos notar que nos casos chileno e peruano a amplitude ideológica dos legisladores é bastante elevada, percorrendo todo o espectro direitaesquerda (1 a -1). Entretanto, no caso chileno, um desvio padrão maior pode indicar maior polarização ideológica quando comparado ao caso peruano. No caso colombiano, a amplitude ideológica é um pouco menor, assim como o desvio padrão, indicando um menor nível de polarização ideológica. As médias ideológicas indicam que no Peru e Colômbia predominam legisladores situados na direita do espectro ideológico, enquanto no Chile a média indica uma posição de centro-esquerda.

O desemprego dos distritos eleitorais revela maiores índices no Chile e Colômbia, sendo que no primeiro caso a dispersão e amplitude são maiores, indicando variabilidade entre os níveis de desemprego entre os distritos eleitorais. No caso colombiano, uma dispersão menor indica que os distritos colombianos enfrentam de maneira mais generalizada elevadas taxas de desemprego. Já no que se refere à porcentagem da população economicamente ativa empregada no primeiro 
setor da economia (PEA $1^{\circ}$ Setor), variável inexistente no caso colombiano, notamos maior concentração rural no Peru, possuindo amplitude, média e dispersão maiores quando comparados ao caso chileno. Finalmente, percebemos que as exportações das regiões peruanas possuem forte assimetria entre as mesmas, apresentando elevados desvio padrão e amplitude, revelando um desvio padrão maior do que a média exportada pelas regiões peruanas. No caso colombiano, ao contrário, a disparidade é menor, apresentando uma menor assimetria entre os distritos eleitorais no que tange as suas exportações.

TABELA 5 - RESULTADOS MODELO LOGÍSTICO TLC PERU-ESTADOS UNIDOS

\begin{tabular}{|l|c|c|c|c|c|}
\hline Variáveis & Coeficiente (B) & Erro Padrão & $\mathbf{Z}$ & p valor & Exp (B) \\
\hline Ideologia & 42.269 & 11.014 & 3.84 & 0.000 & 2.28 \\
Desemprego & .903 & .850 & 1.06 & 0.288 & 2.46 \\
Coalizão & -.058 & 1.310 & -0.04 & 0.965 & 1.06 \\
PEA $1^{\circ}$ setor & .0354 & .071 & 0.50 & 0.620 & 1.03 \\
Exportações & 1.15 & 2.01 & 0.57 & 0.567 & 1.00 \\
Constante & -14.287 & 8.174 & -1.75 & 0.080 & .000 \\
Log Likelihood & -11.151 & & & & \\
Graus de Liberdade & 5 & & & & \\
N de observações & 93 & & & & \\
\hline
\end{tabular}

FONTE: O autor.

\section{IV.1. Peru}

A coluna B (coeficiente) retorna os coeficientes do modelo para cada variável explicativa. $\mathrm{Na}$ coluna erro padrão, é apresentada uma medida de variabilidade desses coeficientes. A estatística Z e o p-valor são utilizados para testar a hipótese de cada coeficiente no modelo de regressão. Segundo Hair (2005), esse teste identifica o quanto a variável explicativa participa individualmente da explicação da variável resposta "voto". No caso do teste Z, obtido por B/Erro Padrão, quanto maior o valor do coeficiente, maior a capacidade explicativa da variável. Como mostra a Tabela 5 , a ideologia do legislador peruano possui um coeficiente de $\mathrm{Z}$ elevado (3.84), indicando a sua relevância explicativa nos votos dos legisladores peruanos. O p-valor da variável ideologia é menor ou igual a 0.01 (0.000 no nosso caso), indicando com um nível de significância de $1 \%$ que esta variável é representativa dos votos dos legisladores. Podemos notar que o sinal do coeficiente da variável "ideologia" é positivo, indicando que o acréscimo em uma unidade na ideologia do legislador (caminhar em direção à direita) acrescenta 42.2 log odds na variável resposta "voto", mantidas as demais variáveis constantes.
A título de exemplo, calcularemos a probabilidade de um legislador peruano de esquerda, com ponto ideal $-1^{10}$, votar favoravelmente ao acordo de livre comércio com os Estados Unidos. A função logística pode ser representada por: $\mathrm{P}(\mathrm{V}=1 \mid$ Ideologia $)=1$ $/\left(1+\mathrm{e}^{-(\text {constante }+ \text { BIdeologiai })}\right)$, em que $\mathrm{f}(\mathrm{y})$ pode ser interpretado como a probabilidade de um legislador votar favoravelmente ao tratado de livre comércio, BIdeologiai é a ideologia do deputado $i$ (no caso, -1). Incluindo os valores presentes na Tabela 4, temos: $\mathrm{P}(\mathrm{V}=1 \mid$ Ideologia $)=1 /\left(1+\mathrm{e}^{-(-}\right.$ $\left.14.287+(42.044)^{*}(-1)\right)=0,30$. Podemos concluir, portanto, que a probabilidade de um legislador peruano ocupar a esquerda do espectro ideológico e votar favoravelmente ao acordo de livre comércio com os Estados Unidos é de 30\%, corroborando a hipótese 4 citada anteriormente.

Adicionalmente, a última coluna da Tabela 5 retorna a razão de chance (odds ratio) para as variáveis preditoras. No caso da variável ideologia, a única estatisticamente significativa no modelo, inferimos que um legislador peruano situado na

10 O espectro ideológico da estimação via Nominate dos pontos ideais dos legisladores peruanos varia de -1 (esquerda) a 1 (direita). Para mais detalhes, ver Feliu, Oliveira e Galdino (2009). 
direita do espectro tem 2,28 vezes mais chance de aprovar o TLC com os Estados Unidos quando comparado a um legislador mais à esquerda do espectro ideológico.

TABELA 6 - RESULTADOS MODELO LOGÍSTICO TLC CHILE-ESTADOS UNIDOS

\begin{tabular}{|c|c|c|c|c|c|}
\hline Variáveis & Coeficiente (B) & Erro Padrão & $\mathbf{Z}$ & p valor & $\operatorname{Exp}(B)$ \\
\hline Ideologia & -5.082 & 2.785 & -1.82 & 0.068 & .006 \\
\hline Desemprego & -.715 & .284 & -2.51 & 0.012 & .489 \\
\hline Coalizão & -2.557 & 3.444 & -0.74 & 0.458 & .077 \\
\hline PEA $1^{\circ}$ setor & -.043 & .0439 & -0.99 & 0.321 & .957 \\
\hline Constante & 12.620 & 3.864 & 3.27 & 0.001 & 2.34 \\
\hline Log Likelihood & -16.362 & & & & \\
\hline Graus de Liberdade & 4 & & & & \\
\hline $\mathrm{N}$ de Observações & 95 & & & & \\
\hline
\end{tabular}

FONTE: O autor.

\section{V.2. Chile}

Assim como o modelo logístico peruano, o chileno, expresso na Tabela 6 acima, revela apenas uma variável estatisticamente significativa quando assumimos um intervalo de confiança de $95 \%$. A diferença reside na variável com maior poder explicativo. Enquanto no Peru a ideologia do legislador apresenta a maior capacidade explicativa, no Chile é o desemprego do distrito eleitoral do deputado a principal variável explicativa, indicada por um p-valor de 0.012 e um coeficiente $\mathrm{Z}$ de 2.51. É interessante notar que o sinal do coeficiente dessa variável é negativo, mostrando que o acréscimo de uma unidade no desemprego distrital decresce -.714 em log odds a variável resposta "voto", mantidas todas as outras variáveis constantes. Em outras palavras, o aumento na taxa de desemprego do distrito eleitoral diminui a probabilidade de um deputado chileno aprovar o TLC com os Estados Unidos. Complementariamente, um deputado proveniente de um distrito eleitoral com elevada taxa de desemprego possui um odds ratio de .489 , ou seja, 0,48 vezes mais chance de rejeitar o TLC do que um deputado representante de um distrito eleitoral com baixo desemprego.
Além da variável desemprego, notamos na Tabela 6 que a variável ideologia, embora não esteja em um intervalo de $95 \%$, poderia ser incluída, como estatisticamente significativa, em um intervalo de 90\%. Assim, apesar da variável ideologia revelar um odds ratio baixo (.006) e um coeficiente $\mathrm{z}$ relativamente baixo (-1.82), é interessante analisar o efeito combinado de ambas as variáveis no voto do deputado chileno no TLC com os Estados Unidos. Para tanto, utilizaremos o programa Clarify para STATA (TOMZ, WITTENBERG \& KING, 2001).

O Clarify utiliza o teste de monte Carlo para fazer simulações nas variáveis preditoras estimadas pelo modelo logístico que auxiliam na interpretação e apresentação dos resultados estatísticos. Assim, são feitas 1000 simulações a partir de quantidades definidas pelo próprio pesquisador (idem). No nosso caso, utilizamos os valores máximos e mínimos das variáveis desemprego e ideologia. Abaixo segue o Gráfico 1 produzido por meio do Clarify. 


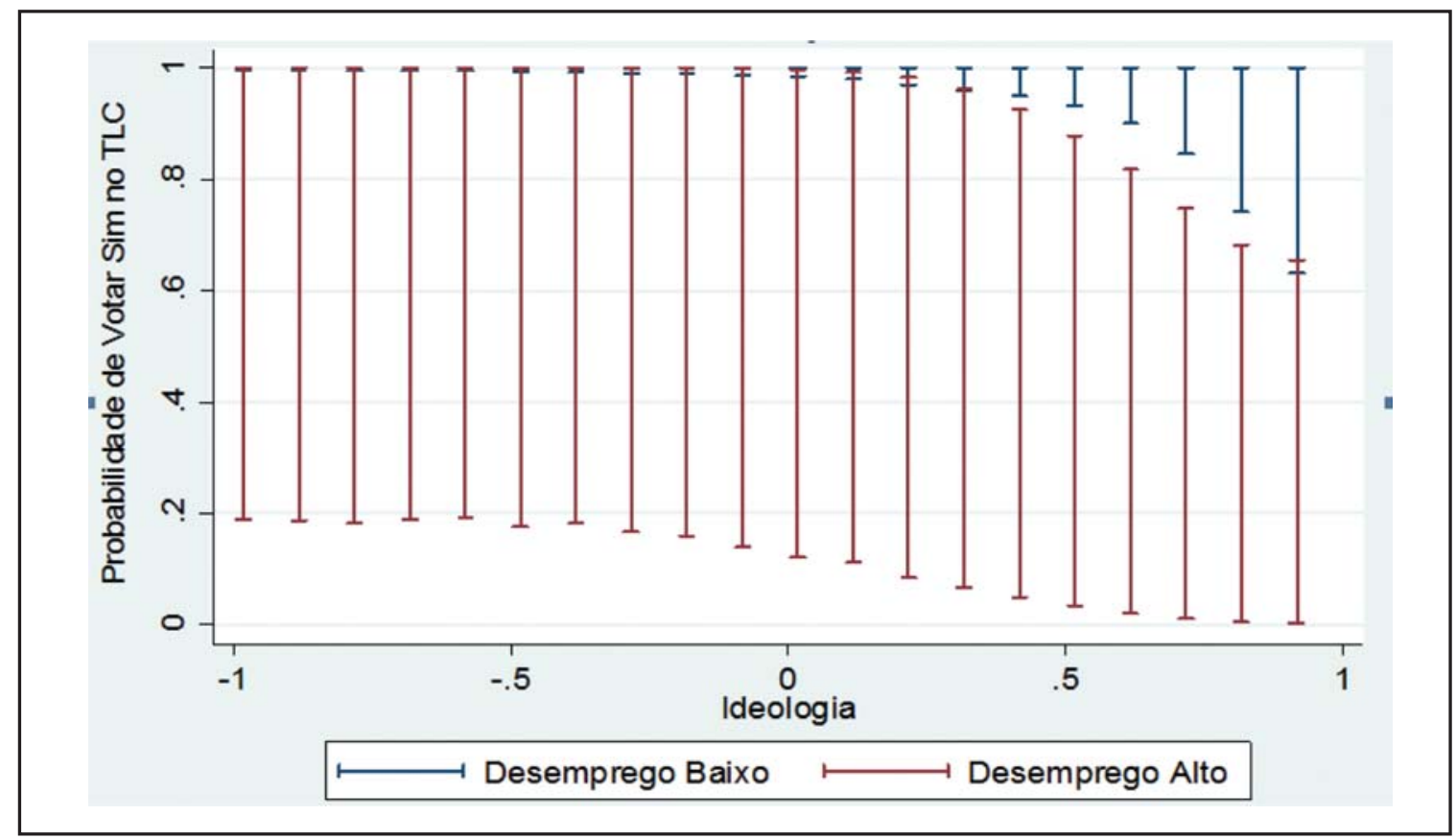

FONTE: O autor.

As barras azuis e vermelhas indicam o intervalo de confiança de $95 \%$ da variável preditora desemprego quando ela assume valores baixos e altos, respectivamente. No eixo vertical encontrase a probabilidade do deputado aprovar o TLC com os Estados Unidos, enquanto que no eixo horizontal a ideologia do mesmo, lembrando que "-1" significa esquerda e " 1 " direita. O primeiro aspecto interessante notado é a elevada probabilidade de um deputado chileno aprovar o TLC com os Estados Unidos quando o desemprego em seu distrito eleitoral é baixo, ainda que esta probabilidade diminua um pouco na medida em que o deputado se situa mais a direita do espectro ideológico. Analogamente, taxas de desemprego altas tornam as decisões dos deputados chilenos, situados na esquerda, mais imprevisíveis, variando de $20 \%$ a $100 \%$ a probabilidade de aprovação do TLC no intervalo de confiança de $95 \%$. Por outro lado, o deputado chileno situado na direita do espectro e representante de um distrito dotado de elevada taxa de desemprego apresenta uma queda na probabilidade de aprovação do TLC com os Estados Unidos, variando de $0 \%$ a aproximadamente $60 \%$.

\section{IV.3. Colômbia}

A votação acerca da aprovação do TLC com os Estados Unidos parece inserir-se perfeitamente na lógica de funcionamento do "presidencialismo de coalizão", isto é, a base de partidos governistas vota de maneira disciplinada nesta importante política externa do governo. A tabela 7 abaixo ilustra a votação cruzando as variáveis "coalizão de governo" e "coalizão de oposição". Simplesmente $0 \%$ dos senadores colombianos pertencentes à base governista votou "não" ao TLC com os Estados Unidos. Analogamente, apenas 5,9\% dos senadores pertencentes à oposição votaram "sim" ao tratado. Para atribuir maior robustez a essa análise, aplicamos o teste qui-quadrado para testar a significância da associação entre pertencer ou não à coalizão de governo e votar sim ou não ao tratado de livre comércio com os Estados Unidos. Dessa forma, testaremos a validade da hipótese nula (há independência entre as variáveis) em detrimento de $\mathrm{H} 1$ (as variáveis possuem um elevado grau de associação). A Tabela 7, abaixo, exibe os valores desse teste. 
TABELA 7 - DISTRIBUIÇÃO SENADORES COLOMBIANOS SEGUNDO COALIZÃO E VOTO NAAPROVAÇÃO DO TLC COLÔMBIA-ESTADOS UNIDOS

\begin{tabular}{|l|c|c|c|}
\hline \multirow{2}{*}{ Coalizão } & \multicolumn{2}{|c|}{ Votos } & \multirow{2}{*}{ Total } \\
\cline { 2 - 3 } & Sim & Não & \\
\hline Governo (\%) & $48(100)$ & $0(0)$ & $48(75,4)$ \\
Oposição (\%) & $1(5,9)$ & $16(94,1)$ & $17(24,6)$ \\
Total (\%) & $49(100)$ & $16(100)$ & $65(100)$ \\
\hline
\end{tabular}

FONTE: $\mathrm{O}$ autor.

TABELA 8 - TESTE QUI-QUADRADO COALIZÃO X VOTO TLC COLÔMBIA - ESTADOS UNIDOS

\begin{tabular}{|l|c|c|c|}
\hline & Valor & Graus de liberdade & Valor p (significância) \\
\hline Pearson qui-quadrado & 59.928 & 1 & .000 \\
Correção de continuidade & 54.963 & 1 & .000 \\
Likelihood Ratio & 64.943 & 1 & .000 \\
N de Casos & 65 & & \\
\hline
\end{tabular}

FONTE: O autor.

Como podemos observar na Tabela 8 , acima, o valor qui-quadrado de 59.928 com um valor $\mathrm{p}$ valor de .000 possibilitam rejeitar a hipótese nula, ou seja, não há independência entre as variáveis coalizão e voto. Assim, aceitamos a hipótese de que há um elevado grau de significância da associação entre pertencer à coalizão de governo e votar sim no TLC Colômbia-Estados Unidos. Complementariamente, a Tabela 8 ainda exibe os valores obtidos para o teste de correção de continuidade e o teste likelihood ratio. O primeiro, realizado apenas para tabelas de contingência $2 \times 2$ (como no nosso caso), consiste em subtrair 0,5 dos valores esperados. Como podemos notar, permanece extremamente significativo (.000) o resultado do teste qui-quadrado. Finalmente, o likelihood ratio representa a razão da máxima probabilidade de aceitar-se ou rejeitar duas hipóteses concorrentes. Valores pequenos desse teste permitem, dependendo do grau de confiabilidade, rejeitar a hipótese. No caso analisado observamos um valor extremamente baixo (.000), garantindo, com $99,9 \%$ de confiança, aceitar a hipótese de que pertencer ou não à base governista está fortemente associado a aprovar ou não o TLC com os Estados Unidos.

TABELA 9 - RESULTADOS MODELO LOGÍSTICO TLC COLÔMBIA-ESTADOS UNIDOS

\begin{tabular}{|l|c|c|c|c|c|}
\hline Variáveis & Coeficiente (B) & Erro Padrão & $\mathbf{Z}$ & p valor & Exp (B) \\
\hline Ideologia & 2.98 & .965 & 3.09 & 0.002 & 19.79 \\
Desemprego & .760 & .822 & 0.92 & 0.355 & 2.13 \\
Exportações & 1.15 & 2.01 & 0.29 & 0.773 & 1.00 \\
Constante & -21.38 & 11.75 & -1.82 & 0.069 & .00 \\
Log Likelihood & -7.864 & & & & \\
Graus de liberdade & 3 & & & & \\
N de observações & 65 & & & & \\
\hline
\end{tabular}

FONTE: $O$ autor. 
Como era esperado, dada a elevada correlação entre as variáveis "coalizão" e "ideologia", esta última configura-se como a principal variável explicativa no modelo exposto na Tabela 9, evidenciado por um coeficiente $Z$ elevado (3.09), assim como um nível de significância estatística de $1 \%$ (p-valor igual a .002). Assim como no caso peruano, o sinal do coeficiente da variável "ideologia" é positivo, indicando que o acréscimo em uma unidade na ideologia do Senador colombiano (caminhar em direção à direita) acrescenta $2.98 \log$ odds na variável resposta "voto", mantidas as demais variáveis constantes. A análise da razão de chance da variável "ideologia" na última coluna da Tabela 9 indica que um legislador colombiano situado à direita do espectro tem 19,7 vezes mais chance de aprovar o TLC com os Estados Unidos quando comparado a um legislador mais à esquerda do espectro ideológico. O modelo logístico exposto na Tabela 9 possibilitou contrastar a variável "ideologia" com as variáveis distritais "exportações" e "desemprego", revelando a sobrevivência desta última como fator explicativo do voto do Senador colombiano no TLC com os Estados Unidos.

\section{CONCLUSÕES}

O presente estudo buscou testar hipóteses presentes na literatura acerca dos determinantes do voto do legislador em política comercial para os casos da aprovação do TLC com os Estados Unidos de Chile, Colômbia e Peru. No caso do Congresso Nacional do Peru, pudemos observar a importância da ideologia do voto do legislador na aprovação, ou seja, há uma clivagem ideológica que polariza as decisões dos congressistas no tema. Situar-se à esquerda do espectro significa uma menor propensão a aprovar o dito tratado. Há, nos legisladores peruanos à esquerda do espectro, a percepção, percebida pelos discursos proferidos em plenário, de que a liberalização comercial, mais especificamente a abertura do mercado peruano aos Estados Unidos, prejudica os pequenos agricultores do país (PERU. CÁMARA DE DIPUTADOS, 2006). Mesmo aqueles legisladores situados mais a esquerda do espectro, cujo distrito eleitoral não seja agrícola, como é o caso de Lima, adotaram essa postura em plenário, evidenciando a influência desta variável no voto.

O sistema partidário peruano sofreu uma importante mudança recente. Após denúncias de compra de votos por parte do governo e a conseqüente renúncia do então Presidente Alberto Fujimori (1990-2000) conduziu o processo político peruano a novas eleições, consagrando em meados de 2001 a eleição de Alejandro Toledo (2001-2006) como Presidente da República ${ }^{11}$. A principal mudança talvez resida no desaparecimento dos partidos chamados fujimoristas nas eleições de 2001, especialmente o Cambio-90 (partido do exPresidente Fujimori) e o surgimento de novas forças políticas, dentre elas o partido do Presidente Toledo, Peru Posible (PP) (CAREY, 2003). Nesse contexto, o apoio majoritário que gozava o Presidente Fujimori no Congresso desaparece na gestão Toledo, ruindo um padrão antes estruturado pela dicotomia entre governo e oposição (HIX \& NOURY, 2011). Esse talvez seja um fator que atribui maior relevância à variável ideologia nesta importante matéria da política comercial peruana, orientando o posicionamento dos legisladores.

No caso chileno, especificamente, a taxa de desemprego do distrito eleitoral influi de maneira mais determinante na decisão do congressista, indicando que quanto maior o índice de desemprego, menor a probabilidade de o deputado votar favoravelmente ao acordo. Quando comparados aos resultados do modelo logístico do Peru, observamos que de uma maneira geral, o modelo chileno possui uma capacidade explicativa menor, fato que pode ser explicado pelo forte apoio que o Congresso Nacional chileno tem demonstrado em plenário nas votações acerca da aprovação de tratados bilaterais de livre comércio (FELIÚ, GALDINO \& OLIVEIRA, 2007). Outro fator que contribui para essa explicação é a ausência de relevância da variável governo versus oposição, tão significativa nos estudos sobre o poder Legislativo chileno em âmbito doméstico (ALEMÁN \& SAIEGH, 2007; MAUREIRA, 2007). Isto é, haveria algo próximo ao bipartisanship norte-americano (MCCORMICK \& WITTKOPFT, 1990) no âmbito das duas coalizões chilenas no que diz respeito à política comercial, mais especificamente a aprovação do TLC com os Estados Unidos. Assim, embora haja polarização no âmbito doméstico, no âmbito comercial haveria um consenso maior restringido pelo tamanho da taxa de desemprego do distrito. Assim, independentemente da coalizão

11 Vale lembrar que o TLC com os Estados Unidos foi aprovado no Congresso peruano no último mês do mandato presidencial de Alejandro Toledo. 
política que assuma o governo chileno, espera-se continuidade na agenda comercial pautada na ampliação de parceiros comerciais via tratados bilaterais de livre comércio, expandindo mercados e mantendo a economia chilena aberta ao mundo.

O caso colombiano demonstrou forte, quase perfeita, associação entre a coalizão política do Senador (governo ou oposição) e seu voto na aprovação do TLC, quando o governo indicava o voto favorável e oposição o voto contrário. A relevância desse fator institucional é bastante presente na literatura que estuda os poderes legislativos do continente e revela uma dinâmica legislativa de coalizões, polarizando as votações nominais dentro desse padrão (ver, por exemplo, Zucco (2009)).

Há dois fatores centrais que incentivam um grau de disciplina relevante entre os legisladores pertencentes à coalizão de governo. O primeiro diz respeito aos significativos poderes legislativos do presidente colombiano, especialmente o poder de agenda e nomeação de cargos, fazendo o presidente um ator político capaz de aglutinar apoio em torno de suas propostas legislativas. Esse é certamente o aspecto institucional central do que a literatura denomina "presidencialismo de coalizão". Segundo, os extraordinários níveis de popularidade do Presidente Álvaro Uribe (20022010) coíbem eventuais resistências dos legisladores pertencentes à coalizão de governo, tornando a aproximação ao presidente uma vantagem eleitoral significativa (MILANESE, 2008). Notamos também a relevância explicativa da ideologia do partido politico do legislador colombiano, indicando que quanto mais a esquerda estiver o partido do legislador, menor a probabilidade de aprovação do TLC com os Estados Unidos. É importante lembrar a forte correlação entre pertencer à coalizão de governo e ser membro de um partido de direita, indicando no caso colombiano a baixa relevância das variáveis distritais.

Os resultados empíricos revelaram a influência de importantes hipóteses presentes na literatura sobre política comercial acerca da aprovação do TLC com os Estados Unidos nos três legislativos sul-americanos. Assim, desemprego, ideologia e o pertencimento ou não à coalizão de governo são variáveis centrais para a compreensão do voto dos legisladores do subcontinente na aprovação do TLC com os Estados Unidos.

Pedro Feliú Ribeiro (pfeliu@uol.com.br) é Doutor em Ciência Política pela Universidade de São Paulo (USP) e Professor de Relações Internacionais na Universidade Federal da Paraíba (UFPB).

\section{REFERÊNCIAS BIBLIOGRÁFICAS}

ALEMÁN, E. \& SAIEGH, S. 2007. Legislative Preferences, Political Parties, and Coalition Unity in Chile. Comparative Politics, New York, v. 39, n. 3, p. 253-272, Apr.

BAILEY, M.; GOLDSTEIN, J. \& WEINGAST. 1997. The Institutional Roots of American Trade Policy: Politics, Coalition and International Trade. World Politics, Princeton, v. 43, n. 3, p. 309-338, Apr.

BALDWIN, R. \& MAGEE, C. 2000. Congressional Trade Votes: from NAFTAApproval to Fast-Track Defeat. Washington DC: Institute for International Economics.

BUENO DE MESQUITA, B. 2000. Principles of International Politics. People's power, preferences and perceptions. Washington (DC): CQ.
CAREY, J. 2003. Transparency Versus Collective Action: Fujimori's Legacy and the Peruvian Congress. Comparative Political Studies, Thousand Oaks, v. 36, n. 9, p. 983-1006, Nov.

CONLEY, R. 1999. Derailing Presidential FastTrack Authority: The Impact of Constituency Pressures and Political Ideology on Trade Policy in Congress. Political Research Quarterly, Salt Lake City, v. 52, n. 4, p. 785-799, Dec.

EHRLICH, D. 2008. The Tariff and the Lobbyist: Political Institutions, Interest Group Politics, and U.S. Trade Policy. International Studies Quarterly, New Jersey, v. 52, n. 2, p. 427445, June.

EPSTEIN, D. \& O'HALLORAN, S. 1996. The Partisan Paradox and the U.S. Tariff, 1877 1934. International Organization, Cambridge (UK), v. 54, n. 2, p. 301-324, Spring. 
FELIU, P.; GALDINO, M. \& OLIVEIRA, A. 2007. Política de comércio exterior, ideologia partidária e interesses locais: um estudo sobre o caso chileno. Cena Internacional, Brasília, v. 9, n. 2, p. 33-57. Disponível em: http:// cafemundorama.files.wordpress.com/2011/11/ cena_2007_2.pdf. Acesso em: 24.mar.2013.

FELIU, P.; OLIVEIRA, A. \& GALDINO, M. 2009. A política externa chilena e o espectro ideológico político-partidário: um Estudo sobre a Câmara dos Deputados do Chile (20022006). Dados, Rio de Janeiro, v. 52, n. 4, p. 835-866. Disponível em: http://www.scielo.br/ pdf/dados/v52n4/v52n4a02.pdf. Acesso em: 24.mar.2013.

FORDHAM, B. \& MCKEOWN, T. 2003. Selection and Influence: Interest Groups and Congressional Voting on Trade Policy. International Organization, Cambridge (UK), v. 57 , n. 3, p. 519-549.

GROSSMAN, G. \& HELPAN, E. 1994. Protection for Sale. American Economic Review, Pittsburgh, v. 84, n. 4, p. 833-850, Sept. Disponível em: http://pages.uoregon.edu/ bruceb/Andrea.pdf. Acesso em: 24.mar.2013.

HAIR, J. 2005. Análise multivariada de dados. $5^{\mathrm{a}}$ ed. Porto Alegre: Bookman.

HALL, R. \& DEARDOFF, A. 2006. Lobbying as Legislative Subsidy. American Political Science Review, Los Angeles, v. 100, n. 1, p. 69-84, Feb.

HANKLA, C. 2006. Party Strength and International Trade: A Cross National Analysis. Comparative Political Studies, Thousand Oaks, v. 39, n. 9, p. 1133-1156, Nov.

HENISZ, W. \& MANSFIELD, E. 2006. Votes and Vetoes: The Political Determinants of Commercial Openness. International Studies Quarterly, New Jersey, v. 50, n. 1, p. 189211, Mar.

HISCOX, M. 2002. Commerce, Coalitions, and Factor Mobility: Evidence from Congressional Votes on Trade Legislation. American Political Science Review, Los Angeles, v. 96, n. 3, p. 593-608, Sept.

HIX, S. \& NOURY, A. 2011. GovernmentOpposition or Left-Right? The Institutional Determinants of Voting in Legislatures.
Working Paper, London School of Economics, London, May. Disponível em: http:// personal.lse.ac.uk/hix/Working_Papers/HixNoury-GOorLR-23March2012.pdf. Acesso em: 24.mar.2013.

KAROL, D. 2007. Does Constituency Size Affect Elected Officials' Trade Policy Preferences? The Journal of Politics, Statesboro, v. 69, n. 2, p. 483-494, May. Disponível em: http:// www.bsos.umd.edu/gvpt/karol/ Karol\%20May\%202007\%20JOP\%20Article.pdf. Acesso em: 24.mar.2013.

LIMONGI, F. 2006. A democracia no Brasil: presidencialismo, coalizão partidária e processo decisório. Novos Estudos, São Paulo, n. 76, p. 17-41. Disponível em: http://www.scielo.br/ pdf/nec/n76/02.pdf. Acesso em: 24.mar.2013.

LOWI, T. 1964. American Business, Public Policy, Case Studies, and Political Theory. World Politics, Princeton, v. 16, n. 4, p. 677715, July.

MANSFIELD, E.; MILNER, H. \& ROSENDORFF, P. 2000. Free to Trade: Democracies, Autocracies and International Trade. American Political Science Review, Los Angeles, v. 94, n. 2, p. 305-321, June. Disponível em: http://www.stanford.edu/class/ polisci243b/readings/v0002547.pdf. Acesso em: 24.mar.2013.

MARKS, G.; HOOGE, L.; NELSON, M. \& EDWARDS, E. 2006. Party Competition and Europeans Integration in the East and West: Different Structure, Same Causality. Comparative Political Studies, Thousand Oaks, v. 39, n. 2, p. 155-175, Mar. Disponível em: http://campus.usal.es/ cedesal/master/ practicas/Sistemas $\% 20 \mathrm{de} \% 20$ partidos/ Marks\%20et\%20al\%20CPS\%202006.pdf. Acesso em: 24.mar.2013.

MAUREIRA, S. 2007. Conducta legislativa ante las iniciativas del Ejecutivo: unidad de los bloques políticos em Chile. Revista de Ciencia Politica, Santiago, v. 27, n. 1, p. 23-41. Disponível em: http://www.scielo.cl/ scielo.php?pid=S0718-090X2007000200002\& script=sci_arttext. Acesso em: 24.mar.2013.

MCCORMICK, J. \& WITTKOPF, E. 1990. Bipartisanship, Partisanship, and Ideology in Congressional - Executive Foreign Policy 
Relations, 1947-1988. Journal of Politics, Cambridge (UK), v. 52, n. 4, p. 1077-1100, Nov.

MCGILLIVRAY, F. 1997. Party Discipline as a Determinant of the Endogenous Formation of Tariffs. American Journal of Political Science, Los Angeles, v. 41, n. 2, p. 584-607, Apr.

MILANESE, J. 2008. Relaciones EjecutivoLegislativo en la actual coyunctura politica colombiana: un análisis desde la lógica de los veto players. Observatorio de Politicas Publicas, Bogotá, policy paper n. 2.

MILNER, H. \& JUDKINS, B. 2004. Partisanship, Trade Policy, and Globalization: is there a leftright divide on trade policy? International Studies Quarterly, New Jersey, v. 48, p. 95119. Disponível em: http://www.princeton.edu/ $\sim$ hmilner/forthcoming $\% 20$ apers/ ISQ_milner_judkins2004.PDF. Acesso em: 24.mar.2013.

MILNER, H. \& KUBOTA, K. 2005. Why the Move to Free Trade? Democracy and Trade Policy in the Developing Countries. International Organization, Cambridge (UK), v. 59, n. 1, p. 107-143, Jan. Disponível em: http://www.princeton.edu/ hmilner/ forthcoming\%20papers/LDCdem_IO.pdf. Acesso em: 24.mar.2013.

MILNER, H. \& ROSENDORFF, P. 1997. Democratic Politics and International Trade Negotiations: elections and divided government as constrains on trade liberalization. Journal of Conflict Resolution, Maryland, v. 41, n. 1, p. 117-146, Feb.

MUSTAPIC, A. 2002. President and Congress in Argentina. In: MORGENSTERN, S. \& NACIF, B. (eds.). Legislative Politics in Latin America. Cambridge (UK): Cambridge University.

NIELSON, D. 2003. Supplying Trade Reform: Political Institutions and Liberalization in Middle-Income Presidential Democracies. American Journal of Political Science, Los Angeles, v. 47, n 3, p. 470-491, July.

NOLTE, D. 2003. El Congreso chileno y su aporte a la consolidación democrática en perspectiva comparada. Revista de Ciencia Política, Santiago, v. 23, n. 2, p. 43-67. Disponível em: http://www.scielo.cl/pdf/revcipol/v23n2/ art03.pdf. Acesso em: 24.mar.2013.

OLIVEIRA, A. \& ONUKI, J. 2010. Eleições, partidos políticos e política externa no Brasil. Política Hoje, Recife, v. 19, n. 1, p. 144-185. Disponível em: http://www.revista.ufpe.br/ politicahoje/index.php/politica/article/view/49/ 30. Acesso em: 24.mar.2013.

OLSON, M. 1982. The Rise and Decline of Nations: Economic Growth, Stagflation and Social Rigidities. New Haven: Yale University.

RAY, E. 1981. The Determinants of Tariff and Nontariff Trade Restriction in United States. Journal of Political Economy, Chicago, v. 89, n. 1, p. 105-121, Feb.

ROGOWISKI, R. 1987. Trade and Variety of Democratic Institutions. International Organization, Cambridge (UK), v. 41, n. 2, p. 203-224, Spring. Disponível em: http:// www.stanford.edu/class/polisci243c/readings/ v0002028.pdf. Acesso em: 24.mar.2013.

1989. Commerce and Coalitions. Princeton: Princeton University.

SAEZ, M. \& RIVAS, C. 2006. The Left-Right Dimension in Latin America Party Politics. Trabalho apresentado no Annual Meeting of the American Political Science Association, realizado em Filadélfia, Estados Unidos, de 31 de agosto a 3 de setembro. Digit.

SAIEGH, S. 2005. The Role of Legislatures in the Policymaking Process. In: INTERAMERICAN DEVELOPMENT BANK. Workshop on State Reform, Public Policies and Policymaking Processes. Washington (DC): Inter-American Development Bank. Disponível em: http://www7.iadb.org/res/ publications/pubfiles/pubs-302.pdf. Acesso em: 24.mar.2013.

TOMZ, M.; WITTENBERG, J. \& KING, G. 2001. Clarify: Software for Interpreting and Presenting Statistical Results. Disponível em: http://www.jstatsoft.org/v08/i01/paper. Acesso em: 24.mar.2013.

ZUCCO, C. 2009. Ideology or What? Legislative Behavior in Multiparty Presidential Settings. The Journal of Politics, Cambridge (UK), v. 71, p. 1076-1092, July. Disponível em: http:// 
www.princeton.edu/csdp/events / Zucco100407/Zucco100407.pdf. Acesso em: 24.mar. 2013.

XIE, T. 2004. Congressional Roll Call Voting on China Trade Policy. American Politics
Research, Louisiana, v. 32, n. 6, pp. 679-697, Nov.

WUENSCH, K. 2009. Binary Logistic Regression with PASW/SPSS. Disponível em: http:// core.ecu.edu/psyc/wuenschk/MV/Multreg/ Logistic-SPSS.pdf. Acesso em: 24.mar.2013.

\section{OUTRAS FONTES}

CHILE. 2013. Sitio da Cámara de Diputados de Chile. Disponível em: http://www.camara.cl/. Acesso em: 24.mar.2013.

CHILE. CÁMARA DE DIPUTADOS. 2003. Sesión $60^{a}$ Especial de 16 de Marzo. República de Chile.

CHILE. CASEN. 2003. Encuesta de Caracterización Socioeconómica Nacional. Ministério de Palinificación y Cooperación de Chile (MIDEPLAN). Disponível em: http:// www.mideplan.cl/casen. Acesso: 15/03/2010.

COLOMBIA. DANE. 2007. Indicadores Económicos y Sociales. Departamento Administrativo de Estatística Nacional. Disponível em: http://www.dane.gov.co. Acesso: 20/04/2010.

CONGRESO VISIBLE. 2008. Balance de La Legislatura 2007-2008. Universidad de los
Andes. Disponível em: http://www.congreso visible.org. Acesso em 24.mar.2013.

PELA. 2006. Proyecto Elites Latino Americanas: estudio 59 (Colombia). Universidad de Salamanca. Disponível em: http:// americo.usal.es/oir/Elites. Acesso em 24.mar.2013.

PERU. 2013. Sitio da Cámara de Diputados. H. Congreso de la Unión. Disponível em: http:// www.diputados.gob.mx/inicio.htm. Acesso em: 24.mar.2013.

PERU. CÁMARADE DIPUTADOS. 2006. Diário de los debates, Sesión $18^{a}$ de 27 de Junio. República de Peru.

PERU. INEI. 2007. Encuesta Permanente de Empleo. Instituto Nacional de Estadística e Informática. Disponível em: http:// webinei.inei.gob.pe/anda/. Acesso: 29/05/2010 
THE LEGISLATURE AND TRADE POLICY: APPROVAL OF THE FTA WITH THE U.S. WITHIN LATIN AMERICAN LEGISLATURES

\section{Pedro Feliú Ribeiro}

This article analyzes how three South American legislatures (Chile, Colombia and Peru) voted regarding the ratification of the Free Trade Agreement with the United States. My central question 
is: "What are the factors that determine a legislator's vote regarding approval of the FTA with the USA? Three central hypotheses emerge from the literature: U.S./Latin America relationships produce an ideological cleavage (right-left) between the political parties of the continent, the significance of whether a legislator belongs to the governing coalition within Legislative Power and socio-economic factors linked to legislators' electoral districts. Through application of the logistic regression model, we argue that the ideology of Peruvian legislators explains how they vote regarding the FTA with the USA, indicating that the further to the left the legislator is, the lesser the probability that he will approve that treaty. In the Chilean case, unemployment rates in Chilean representatives' electoral districts demonstrated greater explanatory ability, revealing that at higher inflation rates, the lesser the probability that the FTA with the USA be approved. In the case of the Colombian senate, there is a strong association between a senator's belonging to the government coalition and FTA approval. This reveals the influence of this institutional variable over votes within the Colombian senate. Beyond belonging or not to the government coalition, the political party ideology of Colombian legislators also operates as a factor explaining voting patterns.

KEYWORDS: Commercial Policy; South American Legislatures; Free Trade Agreement; U.S.A. 

LES ÉTATS-UNIS DANS LES LÉGISLATIFS SUD-AMÉRICAINS

\section{Pedro Feliú Ribeiro}

L'Article analyse les votes nominaux de trois Législatifs sud-américains (Chili, Colombie et Pérou) autour de la ratification du Traité de Libre Commerce avec les États-Unis. La question centrale c'est : Quels sont les facteurs déterminants du vote du législateur dans l'approbation du TLC avec les États-Unis? Trois hypothèses centrales émergent de la littérature : les relations États-Unis avec l'Amérique Latine produisent un clivage idéologique (droite-gauche) entre les partis politiques du continent, l'appartenance du législateur à la coalition de gouvernement dans le pouvoir Législatif et les facteurs socio-économiques des districts électoraux des législateurs. En utilisant le modèle de régression logistique, nous soulignons que l'idéologie des législateurs péruviens explique leurs votes dans le TLC avec les États-Unis, ce qui indique que, le plus à gauche est le législateur, la plus petite probabilité que le traité mentionné soit approuvé. Dans le cas chilien, le taux de chômage du district électoral du député chilien a un plus grande capacité explicative, ce qui révèle que, le plus haut est le taux de chômage, la plus petite probabilité de l'approbation du TLC avec les États-Unis. Dans le cas du sénat colombien, il y a une forte association entre l'appartenance du sénateur à la coalition de gouvernement et l'approbation du TLC, révélant l'influence de cette variable institutionnelle dans le vote du Sénat colombien. En plus de l'appartenance ou non à la coalition de gouvernement, l' idéologie du parti politique du législateur colombien est présentée aussi autant qu' un facteur explicatif important de son vote.

MOTS-CLÉS: politique commerciale; Législatifs Sud-américains; traité de libre commerce; États-Unis. 